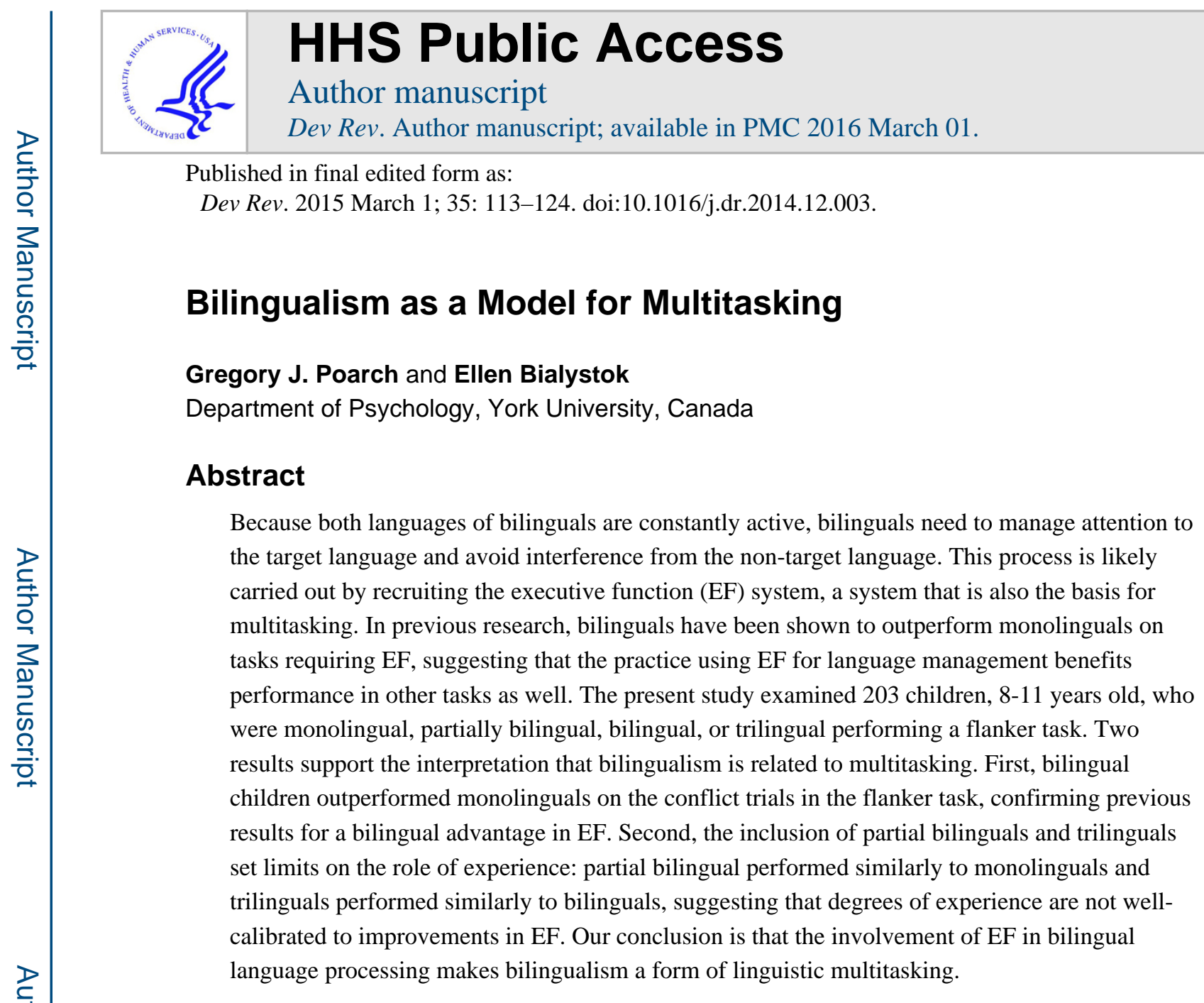

\title{
Keywords
}

bilingualism; executive functions; multitasking; task switching; dual-task performance; monitoring; attention; inhibition

\begin{abstract}
Roughly half of the world's population is bilingual or multilingual, with many more in the process of becoming bilingual (Bhatia \& Ritchie, 2013). Thus, a significant portion of people regularly exist in a sustained and unique dual-language situation: Every act of language processing calls for the recruitment of mental resources to control attention to two (or possibly more) languages. We shall argue that this bilingual situation constitutes a special type of multitasking and that the consequences of this linguistic multitasking may have implications for understanding other dual task situations that children encounter in development.
\end{abstract}

\footnotetext{
(c) 2014 Elsevier Inc. All rights reserved.

Corresponding author: Ellen Bialystok, Department of Psychology, York University, Toronto, ON, Canada M3J 1P3., ellenb@yorku.ca.
}

Publisher's Disclaimer: This is a PDF file of an unedited manuscript that has been accepted for publication. As a service to our customers we are providing this early version of the manuscript. The manuscript will undergo copyediting, typesetting, and review of the resulting proof before it is published in its final citable form. Please note that during the production process errors may be discovered which could affect the content, and all legal disclaimers that apply to the journal pertain. 
There is substantial converging evidence that both languages in bilinguals are constantly active to some degree even if only one is supported by the environment (for review, see Kroll, Dussias, Bogulski, \& Valdes-Kroff, 2012). Therefore, in order to ensure fluent language processing without intrusions from the unwanted language there needs to be a cognitive mechanism that controls attention to the two jointly activated systems and selects correctly for the context. The system generally attributed with this function is the executive control or executive function (EF) system (Abutalebi \& Green, 2008), a set of processes situated in the frontal lobes (Stuss, 2011; Stuss \& Benson, 1986). In an influential analysis of the construct, Miyake and colleagues (Miyake et al., 2000; Miyake \& Friedman, 2012) identified three core components of EF: (1) monitoring and mental set shifting, (2) updating and working memory, and (3) selective attention and inhibition. All these components are immature in infants and develop slowly across early childhood (e.g., Garon, Bryson, \& Smith, 2008).

Central to this argument is the assumption that both languages are jointly activated, creating the need for a cognitive mechanisms to avoid intrusion even when bilinguals are in exclusively monolingual settings. There is substantial evidence for this claim that includes studies with participants of different ages, speaking different languages, and using different empirical methodologies (e.g., Poarch \& Van Hell, 2012a; Rodriguez-Fornells, Rotte, Heinze, Nösselt, \& Münte, 2002; Thierry \& Wu, 2007; Van Heuven, Schriefers, Dijkstra, \& Hagoort, 2008). For example, in a study with Russian-English bilinguals conducted by Marian, Spivey, and Hirsch (2003), eye movements were recorded during an English-only task. Participants saw a display of four pictures and were asked to make an eye movement towards the one that was named, but pictures whose Russian names sounded like the English target word elicited a significant number of initial eye movements. Thus, an instruction to look at the "marker" elicited eye movements to a picture of a stamp, called "marka" in Russian. Therefore, in spite of all instructions and all test materials being in English and despite the English context in which the experiment was conducted, performance of the bilinguals was influenced by Russian, a language not required for the task or by the context.

Other evidence for dual-language activation was found in a go/no-go task using eventrelated potentials (ERP). Wu and Thierry (2012) asked Chinese-English bilinguals to make visual form judgments on shapes (go), while withholding a response when an English word was shown (no-go). During the task, a shape appeared on the screen and participants were instructed to press one of two buttons to indicate whether it was a circle or a square (go) while intervening English words were presented with instruction to refrain from pressing either button (no-go). Critically, some of these to-be-ignored English words resembled the sound of the Chinese translations of the words for "circle" (yuán) or "square" (fāng). For example, one of the stimuli was the English word 'reason', for which the Chinese translation is 'yuán yin'. On these trials, participants were influenced by the irrelevant word and chose the button press associated with the word rather than the shape, similar to the interference in a Stroop task. In the control condition, there was no phonological or semantic relation between the English words, their translation equivalent in Chinese, and the subsequent shape. Event-related potential amplitudes revealed greater inhibitory processing in the conflict trials than in the control condition. The authors interpreted this pattern as indicating parallel access to translation equivalents in the native language during involuntary second 
language processing in a non-verbal task. At the same time, this dual activation also necessitated rapid inhibition of the first language (Chinese) to avoid adversely affecting performance in the nonverbal task.

\section{Bilingualism and executive functioning}

It is the joint activation of the two languages that creates the need for the recruitment of EF in ordinary linguistic tasks by bilinguals. Crucially, multitasking is also strongly dependent on EF. The central argument, therefore, is that bilingual language use is a special case of multitasking and the claim is that the use of EF to manage attention to two languages strengthens EF processes for other purposes. By implication, therefore, bilinguals should be better multitaskers than monolinguals. Consistent with this argument, a large body of evidence has shown that all the EF components are enhanced in bilinguals, both for children (for meta-analysis, see Adesope, Lavin, Thompson, \& Ungerleider, 2010), and adults (for review, see Bialystok, Craik, Green, \& Gollan, 2009). Bilingual children and adults perform better than monolinguals in tasks that involve conflict induced by task-irrelevant information such as the flanker task (Carlson \& Meltzoff, 2008; Costa, Hernández, \& Sebastián-Gallés, 2008; Emmorey, Luk, Pyers, \& Bialystok, 2008; Marzecová, Asanowicz, Krivá, \& Wodniecka, 2013; Nicolay \& Poncelet, 2012; Pelham \& Abrams, 2014; Poarch \& Van Hell, 2012b), the Simon task (Bialystok, Craik, Klein, \& Viswanathan, 2004; Martin-Rhee, \& Bialystok, 2008), and the Stroop task (Bialystok, Craik, \& Luk, 2008, Blumenfeld \& Marian, 2011; Hernández, Costa, Fuentes, Vivas, \& Sebastián-Gallés, 2010). These tasks require conflict resolution to deal with the distracting cues, efficient switching between different trials types, and maintenance of the relevant rules for the task in working memory.

These bilingual advantages in controlling attention, particularly when there is conflict, appear not to depend on experience in using language, that is, language production. Research on preverbal infants has shown that even in early stages of language acquisition, exposure to more than one language affects nonverbal attentional processing. In an eyetracking study, Kovács and Mehler (2009) compared 7-month-old bilingual and monolingual infants on a simple visual attention task. The bilingual infants had been exposed to two parental languages in the home since birth whereas monolingual infants had been exposed to only one language. In three experiments, infants were taught to respond to a speech stimulus cue or a visual pattern cue in anticipation of a reward (a puppet) that would appear on the left or the right side of a screen. Both groups of infants performed equally well predicting the position of a visual reward in the learning phase. For the experimental phase, the location of the reward was switched and the infants had to redirect their anticipatory looks to the opposite side of the screen. The switched location necessitated suppression of the first learned response and switching to a new response. The bilingual infants managed to update their predictions as to where the visual reward would appear while the monolingual infants did not. The authors interpreted their results as indicating accelerated development of general executive functioning in these infants stemming from perceiving and processing utterances from two language sources from birth.

Evidence for an attentional advantage in bilingual infants extends to linguistic tasks. In a study by Weikum et al. (2007), 6-month old infants could discriminate between an 
individual speaking English from the same individual switching and speaking an unfamiliar language, French, on the basis of visual facial cues only but failed to make the discrimination by 8 months old. In contrast, infants being raised in homes in which they were exposed to both English at French were successful in making this discrimination and could detect when the speaker switched languages by watching the silent video. This result indicates that, compared to monolingual children, bilingual infants maintain the ability to visually discriminate between languages based on their need to separate and process multiple languages. A recent study by Sebastián-Gallés, Albareda-Castellot, Weikum, and Werker (2012) extended this research to determine whether familiarity with the language or a more general attentional discrimination was responsible. They assessed the ability of 8month-old Spanish-Catalan infants to visually discern language switches from French to English and from English to French from facial cues only while watching silent videos. Spanish-Catalan bilingual and Spanish and Catalan monolingual infants were shown silent video clips of a bilingual adult reading sentences in French or English (the same materials used in the study by Weikum et al., 2007) until infants were habituated. Following habituation, the infants' looking times were recorded to the speaker continuing to speak in the same language or switching to the other language. Importantly, neither of these languages was familiar to any of the infants. The authors found that the Spanish-Catalan bilingual infants could discriminate between English and French but the Spanish and Catalan monolingual infants could not. The authors interpreted these results as indicating that bilinguals who need to process dual-language input from birth accrue general cognitive advantages and that these advantages stem from the need to separate languages during language acquisition. The primary evidence of this cognitive advantage in infancy is in better attentional processing.

Evidence for superior non-verbal executive function and conflict resolution in bilingual children has been reported in a number of studies (e.g., Adi-Japha, Berberich-Artzi, \& Libnawi, 2010; Poulin-Dubois, Blaye, Coutya, \& Bialystok, 2011; Yang, Yang, \& Lust, 2011). For example, Carlson and Meltzoff (2008) administered executive function tasks to children who were English monolinguals, English-Spanish bilinguals, or English-speaking children enrolled in a second-language immersion elementary school. The bilingual children showed better performance on the executive function tasks than did both other groups. Critically, this advantage did not extend to suppressing a motor response on delay-ofgratification tasks (response inhibition) but was significant on conditions in which memory and inhibition of attention to a prepotent response was required (interference suppression; $\mathrm{cf}$. Martin-Rhee \& Bialystok, 2008). This study also highlighted the conclusion that enhanced executive functioning may require sustained bilingual exposure beyond the 6-month period that the group of immersed children had experienced (see also Poarch \& Van Hell, 2012b, for similar results with children who had been immersed for approximately 15 months).

\section{Bilingualism and multitasking}

Few of the studies investigating bilingualism and executive functioning have used paradigms traditionally considered to be tests of multitasking, but there are some exceptions. Bialystok (2011) reported a study in which 8-year-old children who were monolingual or bilingual completed two tasks in which they were asked to classify either sounds or pictures 
as belonging to the category of animals or musical instruments. Children in both groups completed both tasks equivalently, but when the tasks were combined and children were required to perform both at the same time, the bilingual children maintained a significantly higher level of performance than did the monolingual children. Thus it appears that they were more skilled in managing two concurrent tasks when there was interference and competition between them. Our interpretation is that this task is easier for bilingual children because they function in a constant state of linguistic multitasking.

Unlike the limited research investigating multitasking in bilinguals, there is a larger literature examining language processing and switching in bilinguals, situations that inherently involve multitasking. Like monolinguals, bilinguals need to construct contextually-driven speech plans for speech production. Additionally, however, bilinguals also need to selectively attend to target language structures while resolving competition from the other language and monitor the languages to allow shifting between them if necessary. Green (1998) proposed an inhibitory control mechanism that prevents the nontarget language from intruding into the speech plan (see also Costa, 2005; Kroll, Bobb, Misra, \& Guo, 2008). At a later stage during lexical retrieval, the activation of competitors in the non-target language is reduced through inhibitory processes to resolve competition and enable selection only within the target language. According to Green, bilinguals continuously call upon this inhibitory control mechanism and so accrue massive amounts of experience in control, the accumulation of which may alter the neural organization underlying executive functions (e.g., Abutalebi, 2007; Abutalebi et al., 2008, 2012; see also Stocco, Yamasaki, Natalenko, \& Prat, 2014, for a model combining bilingualism, executive functions and neural information processing).

These changes in executive function are found not only in behavioral performance but also in brain structures involved in the executive function system. Specifically, bilinguals have greater grey matter density in the left putamen (Abutalebi et al., 2013) and the left inferior parietal lobule (Mechelli et al, 2004) than monolinguals. Abutalebi and colleagues (2012) explored whether bilinguals control their languages relying on a neural system that is shared with general cognitive processes. In a number of neuroimaging studies, they found that both language control and cognitive control were subserved by the dorsal anterior cingulate cortex (ACC) in bilinguals, both regions central to the executive function. Critically, when comparing bilinguals and monolinguals, bilinguals showed more efficient use of the ACC during the monitoring of cognitive conflict in non-verbal tasks, a finding replicated by Gold et al. (2013) with older bilinguals. Abutalebi and colleagues interpreted these results as indicating better adaptation to conflicting situations based on the bilinguals' need to control sustained language conflict. Hence, bilingualism induces experience-driven neurocognitive changes from which bilinguals may benefit processing in non-verbal domains.

The important finding in these studies is bilingual language control is subserved by the same neural regions as those engaged by domain-general executive control. Evidence for this conclusion comes from language switching and nonverbal task-switching studies (see Abutalebi \& Green, 2007, 2008; Luk, Green, Abutalebi, \& Grady, 2012, for reviews). Taskswitching paradigms traditionally invoke a local switch cost, calculated as the difference in reaction times between task-switch trials and non-switch trials (e.g., Monsell, 2003; see also 
reviews by Koch, Gade, Schuch, \& Philipp, 2010; Schneider \& Anderson, 2010).

Furthermore, the magnitude of this local switch cost depends on the relative difficulty of the two tasks. Specifically, when the two tasks vary in difficulty, local switch costs are generally smaller when switching from the easy task into the more difficult task than when switching from the difficult task into the easier one. Allport, Styles, and Hsieh (1994) explain this asymmetry in terms of the task-set inertia hypothesis, in which switching costs are assumed to stem from the need to retrieve task-sets inhibited in previous trials (see also Vandierendonck, Liefooghe, \& Verbruggen, 2010; Yeung \& Monsell, 2003). Performing a difficult task requires relatively less inhibition of the easier tasks than does the ability to perform an easy task while attempting to inhibit interference from the more difficult task. Hence, in the subsequent trial either weak or strong inhibition that had been implemented in the previous trial needs to be overcome. This difference in the level of inhibition required in switching between tasks that vary in difficulty gives rise to an asymmetrical switch cost. In contrast, for tasks that are comparable in difficulty and therefore require similar levels of inhibition of the irrelevant task to execute, switches in both directions are similar in magnitude, creating a symmetrical switch cost.

Meuter and Allport (1999) extended this line of research to examine task-switching between two languages. They found that low-proficient bilinguals showed asymmetrical switch costs with larger switch costs when switching from the weaker, more difficult language (L2) into the dominant, easier language (L1) than vice versa, a finding that is in line with results from nonverbal task-switching research. The larger the proficiency difference between languages, the larger the difference in the magnitude of inhibition between the switch from L1 to L2 (easier switch since less inhibition of L2 is necessary while performing in L1) and from L2 to L1 (more difficult switch because of the need for stronger inhibition of L1 while performing in L2). It would follow, therefore, that bilinguals with more balanced proficiency in the two languages would show more symmetrical switching costs because the two tasks are more equivalent in difficulty. This pattern was reported in a study by Costa and Santesteban (2004), in which highly proficient Catalan-Spanish bilinguals switched between languages and demonstrated comparable switching costs when switching from L1 to L2 and from L2 to L1.

The language studies described above demonstrate the constant effort exerted by bilinguals to switch between their two languages. What happens when bilinguals need to switch between two nonverbal tasks? Studies comparing monolinguals and bilinguals have shown smaller switch costs in these tasks for bilinguals than for monolinguals, indicative of more efficient task shifting processes (Garbin et al., 2010; Prior \& Gollan, 2011; Prior \& MacWhinney, 2010; Wiseheart, Viswanathan, \& Bialystok, in press). However, in a recent review Bobb and Wodniecka (2013) suggest that the costs in verbal and non-verbal switching tasks may not necessarily be related to an inhibitory mechanism but rather to the persistence of activation of the task that has become irrelevant (see Philipp, Gade, \& Koch, 2007). Thus, bilinguals may develop an increased ability to resist this interference from the previous task when switching to the new task. This ability in highly-proficient bilinguals may also extend to switching between two established languages and a third less proficient 
language (see Costa, Santesteban, \& Ivanova, 2006, for symmetrical switching costs in highly proficient trilinguals).

Task switching is the basis of multitasking, but task switching itself is not a dichotomous concept in which pairs of trials require either the same (non-switch) or a different (switch) task rule. Salvucci and colleagues (Salvucci, Taatgen, \& Borst, 2009; Salvucci \& Taatgen, $2008,2011)$ proposed a continuum based on the time span between switches. In this scheme, concurrent tasks are those tasks that are performed essentially simultaneously with more time-sequential tasks spread along the continuum, such as switching between reading an email and writing a response. The cognitive demands of concurrent tasks depend on such processes as shifting and allocating resources, attentional control, and inhibition of the lessrelevant task. These processes are decreasingly involved as time between switches increases along the continuum. Thus, greater time between tasks would presumably involve less EF.

Just as task switching can be considered on a continuum, so too can bilingualism. Gradations in bilingualism can be described in terms of either the relative proficiency between the two languages (as in the difference between partial bilinguals and highlybalanced bilinguals) or between the number of languages the individual speaks (as in the difference between bilinguals and trilinguals). If the EF advantages found for bilingualism reflect practice, then greater practice through either degree of bilingualism or number of languages should induce a greater advantage. Regarding degree of bilingualism for children, Bialystok and Barac (2012) reported that more time in an immersion education program was significantly associated with greater benefit on EF tasks, specifically a flanker task or taskswitching paradigm. Using a different approach, Poarch and Van Hell (2012b) compared the performance of children who were monolinguals, second-language learners, bilinguals, or trilinguals and found significantly better performance by multilinguals than monolinguals, with second-language learners partway between these groups. This pattern is consistent with the notion of a continuum of language experience, although there was no effect of the number of languages on EF outcomes.

To summarize, the argument is that bilingual experience enhances the set of EF processes that are central for multitasking so by implication, bilingual children should be better multitaskers than monolinguals. However, two kinds of evidence are needed to support this argument. First, recent studies have challenged the assumption that bilingualism leads to enhanced EF, the key mechanism for these effects. For example, Duñabeitia et al. (2014) compared monolingual and bilingual children across a wide range of ages performing verbal and non-verbal Stroop tasks based on EF and found no significant difference between groups. However, little information was provided about the language abilities of these children, so it is important to confirm there is a bilingual $\mathrm{EF}$ advantage in a group for whom language proficiency is known. Second, if the bilingual advantage in EF is essentially a practice effect in which these EF processes are used for language switching, then being more bilingual should result in a greater EF advantage. Therefore, a more detailed description of bilingualism is required. Although the present study did not directly compare monolingual and bilingual children in a multitasking paradigm, it addressed these two issues to evaluate the argument that bilingualism should be associated with better multitasking. 
To investigate the hypothesis of an EF advantage in bilingual children and its relation to degree of bilingualism, the present study examined four groups of children - monolinguals, partial bilinguals, balanced bilinguals, and trilinguals - for their performance on a standard EF task, namely, the flanker task. The hypotheses were that (a) carefully selected balanced bilinguals would outperform monolinguals on this EF task, confirming a bilingual advantage in an essential aspect of EF, and (b) greater practice with bilingualism would lead to greater benefit, so that balanced bilinguals would outperform unbalanced bilinguals on this task and that trilingual children would outperform bilinguals.

\section{Method}

\section{Participants}

Participants were 203 children, 8 - to 11 -year old, who attended public elementary schools. Sixty children were English monolinguals ( 31 girls and 29 boys), 44 children were being educated in French but used it only in school so were partially bilingual (26 girls and 18 boys), 60 were fully bilingual ( 28 girls and 32 boys), and 39 were trilingual ( 21 girls and 18 boys). The children's mean age was 9.5 years $(S D=0.9$; range $=8.1-11.9$ months $)$.

Parents provided signed consent and completed a Language and Social Background Questionnaire (LSBQ; Luk \& Bialystok, 2013) describing the home language environment and proficiency in each language. The partial bilinguals were all native speakers of English and had been learning French for an average of 2.0 years $(S D=0.7)$. The bilingual children lived in homes in which English was not the primary language but English was used outside the home and in school, and the trilinguals spoke two languages at home in addition to English. Parents were asked to rate their children's daily language usage on a set of 7-point scales that extended from "All English" (1) to "Only other language" (7). An average score of 4 indicates that home communication was divided equally between the languages. The mean score across these scales for monolinguals was $1.2(S D=0.2)$ and for partial bilinguals $1.6(S D=0.6)$, indicating that the homes functioned primarily in English. The mean scores in the bilingual and trilingual groups were $3.0(S D=1.2)$ and $3.3(S D=1.4)$, respectively, indicating a more balanced use of English and the other language(s), $F(3,199)=63.5, p<$. 001. Tukey HSD posthoc analyses indicated that bilinguals and trilinguals had significantly more use of non-English languages in their homes than monolinguals and partial bilinguals, $p$ s <.001, with no difference between bilinguals and trilinguals, $p=.52$, and no difference between monolinguals and partial bilinguals, $p=.15$. Socioeconomic status (SES) was indexed by parents' education using a 5 -point scale $(1=$ not completed high school; $2=$ high school diploma; $3=$ some postsecondary education; $4=$ bachelor's degree; $5=$ graduate or professional degree). There were no differences between groups, $F \mathrm{~s}\langle 2, p\rangle .12$. Background measures are reported in Table 1.

The bilingual and trilingual groups were heterogeneous; there were 22 non-English languages for the bilinguals including Bengali (1), Cantonese (3), Farsi (2), French (5), German (3), Gujarati (4), Hindi (3), Italian (2), Kutchi (1), Lithuanian (1), Mandarin (3), Polish (2), Punjabi (5), Russian (3), Serbian (1), Spanish (2), Tagalog (4), Tamil (4), Telugu (2), Twi (4), Urdu (2), and Vietnamese (3). There were 20 non-English languages for the trilinguals including Arabic (2), Cantonese (3), French (29), Greek (2), Gujarati (4), Hindi 
(3), Italian (3), Japanese (1), Khmer (4), Mandarin (4), Polish (3), Punjabi (4), Spanish (1), Somali (4), Tajik (1), Tamil (3), Teochew (1), Twi (3), Vietnamese (2), and Yoruba (1).

Tasks

Participants completed all tasks in a single 30-minute session. Children were tested individually in a quiet space in their schools by a trained experimenter. Following the session, children were thanked for their help and given stickers as a small gift.

Peabody Picture Vocabulary Test-The Peabody Picture Vocabulary Test (PPVT-III, Dunn \& Dunn, 1997) is a standardized test of receptive vocabulary. Participants are shown test plates of four pictures, one of which the experimenter names. The pictures are blackand-white line drawings of objects, actions, or concepts and participants are required to indicate the named image. The plates become increasingly difficult as the test proceeds. Testing is discontinued once the participant makes 8 errors in a given block of 12 trials. The raw scores are then converted to standard scores based on the participant's age.

Raven's Colored Progressive Matrices-The Raven's test (Raven, Raven, \& Court 1998) is a measure of nonverbal visuospatial reasoning. Two arrays of colored pictures are shown to the participant: one picture forms a pattern and a second one depicts potential components of the pattern. The participant must indicate the picture in the second array that best matches the picture in the first array. Results are calculated as standard scores, which are corrected for age.

Executive functions task-The executive functions task was a modified flanker task (Eriksen \& Eriksen, 1974). Children were asked to indicate the direction in which a target chevron in the middle of an array of five chevrons was pointing by pressing one of two mouse buttons positioned on either side of the computer. There were four types of trials. In baseline trials, only one chevron was shown in the middle of the screen and participants indicated if it was pointing left or right by pressing the mouse key on the left or right side of the computer. In neutral trials, the middle chevron was flanked by two diamonds. In congruent trials, the flanking chevrons pointed in the same direction as the target, but in incongruent trials, the target and flanking chevrons pointed in opposite directions. Trials began with a $500 \mathrm{~ms}$ fixation prior to stimulus onset. The trial terminated either after a subject response or a time-out after $3000 \mathrm{~ms}$. All trials within each block were counterbalanced with right/left responses. The experiment was presented in five blocks. First was a block of 24 baseline trials followed by one block of 24 neutral trials. After this was a mixed block of 24 congruent and 24 incongruent trials with presentation of congruent and incongruent trials generated randomly by the E-prime program. After this, there was another block of 24 neutral trials and then another block of 24 baseline trials. Only RTs of correct responses were included in the analysis.

\section{Results}

Results from demographic background, English vocabulary, and nonverbal intelligence measures are presented in Table 1. One-way ANOVAs showed that the children in the four groups did not differ in English vocabulary and nonverbal intelligence, $F \mathrm{~s}<1.2, p \mathrm{~s}>.30$. 
Mean response times (RT) and mean accuracy rates were calculated for each condition of the flanker task. Incorrect responses (5.1\% for the baseline condition, $5.8 \%$ for the neutral condition, $3.9 \%$ for the congruent condition, and $8.1 \%$ for the incongruent condition) were excluded from the RT analysis. Outliers with RTs shorter than $200 \mathrm{~ms}$ or longer than 2000 $\mathrm{ms}$ and $2.5 \mathrm{SD}$ below or above the mean (4.8\% for the baseline condition, $4.6 \%$ for the neutral condition, $4.7 \%$ for the congruent condition, and $5.1 \%$ for the incongruent condition) were also excluded from the RT analyses. Accuracy and RT data are presented in Table 2. Accuracy was at ceiling so no further analyses were conducted.

For RT scores, separate one-way ANOVAs on baseline and neutral trials to establish whether there were speed of processing differences between groups showed no significant group effect, $F \mathrm{~s}<1$. RTs for the two trial types of interest in the flanker task, the congruent and incongruent trials were analyzed using repeated measures mixed ANOVAs with trial type (congruent and incongruent) as within-group variable and language group (monolinguals, partial bilinguals, bilinguals, and trilinguals) as between-group variable. The RT analysis yielded a main effect of trial type, $F(3,199)=225.20, \eta^{2}=.58, p<.001$, no effect of language group, $F(3,199)<1, \eta^{2}<.01, p=.73$, and an interaction between trial type and language group, $F(3,199)=11.5, \eta^{2}=.06, p<.001$. Tukey HSD posthoc analyses showed that bilinguals and trilinguals were significantly faster at resolving conflict than monolinguals and partial bilinguals, $p s<.02$, on the incongruent trials. Critically, bilinguals and trilinguals did not differ significantly from each other, nor did monolinguals and partial bilinguals, $p s>.50$. The results indicate that the bilinguals and trilinguals were better at resolving conflict than the monolinguals and partial bilinguals. This interpretation was confirmed by a separate one-way ANOVA on the conflict magnitudes (incongruent condition RTs- congruent condition RTs), $F(3,199)=11.50, \eta^{2}=.15, p<.001$.

\section{Discussion}

The purpose of this study was to establish differences between monolingual and bilingual children performing a standard executive function task and relating that performance to the executive control demands of the task (mixed conflict block vs. neutral block) and the degree to which children were bilingual (partial bilinguals, bilinguals, or trilinguals). The results support the hypothesis for EF advantages in bilingual children performing a nonverbal conflict task but only partially support the practice hypothesis in which these advantages would be calibrated to the degree of bilingualism.

The novel design feature of the study was to extend previous research that had focused on monolinguals and bilinguals and include children who were partial bilinguals and speakers of more than two languages. The prediction was that these would be additional points on a continuum in which greater EF advantages would be found with greater bilingual experience. Importantly, children in the four groups did not differ in global reaction times (RT), indicating equal task monitoring abilities across groups. However, the bilingual and trilingual children showed significantly less interference in the incongruent condition and thus were better at resolving conflict than were the monolinguals and partial bilinguals, with no significant differences within these pairs. Therefore, the results from our study provide no evidence to support the idea that controlling three languages instead of two languages 
provides an additional boost to the efficacy of the attentional control system. Similarly, there is no evidence that being partially bilingual was sufficient to distinguish these children from monolinguals on this nonverbal EF task. Thus, if there is an experience-based gradient that is associated with EF performance, it was not properly captured in the four groups included in this study. Instead, the results are in line with a more dichotomous view in which children who are fully bilingual or trilingual demonstrate an EF advantage over those who are not.

Speakers who use more than one language on a regular basis need to control which language to choose in a given context and prevent interference from the language not in use. This process makes all language use by bilinguals a model for linguistic multitasking. The current study demonstrated that more experience in bilingual language processing was associated with better performance on an EF task. Although the EF task used in this study was not a measure of task switching or multitasking, it incorporates the essential elements of those tasks, namely, selection, inhibition, and response shifting.

Two important results from the present study support our interpretation regarding multitasking. First, the proficient bilingual and trilingual children performed significantly better than the monolingual children on the conflict condition of the task. Some recent research has reported that these effects were not found and that there was no difference between monolingual and bilingual children on such tasks (e.g., Duñabeitia et al., 2014). Thus, the present results add to the body of literature demonstrating these advantages in bilingual children (see Adesope et al., 2010 for review and meta-analysis).

Second, the results provide a hint regarding why some studies may not find these differences between monolingual and bilingual children. The majority of the literature provides little documentation of the language abilities and language experiences of children assigned to the monolingual or bilingual groups. Instead, researchers rely on global assessments from parents, teachers, or others with little constraint on how the decisions were made. Consequently, it is conceivable that not all children in the monolingual group are completely monolingual and not all children in the bilingual group are completely bilingual. As seen in the present study, partially bilingual children performed comparably to monolingual children. Therefore, without adequate control over designations as monolingual or bilingual, no group differences would be expected to emerge.

Our interpretation of these results is that the lifelong use of two or more languages can be viewed as a constant form of multitasking. Multitasking has become commonplace in our daily lives; depending on the environment, it has been shown to have positive and negative effects. Driving a car, for example, and at the same time texting on a mobile phone may put the driver and other motorists and pedestrians in danger. Doctors in hospitals and air-traffic controllers, in contrast, may need to multitask in order to manage and perform all their tasks efficiently. There is, furthermore, evidence that some individuals display the ability to perform complex multitasking with very little cost compared to most others who show decreased performance (see Watson \& Strayer, 2010, for so-called supertaskers). The experience of bilingualism may be a facilitatory form of multitasking, all the more so since a linguistic experience of juggling and controlling two languages evidently has an enhancing 
effect on nonverbal executive processing. As such, bilingualism demonstrates the capacity for human multitasking.

Finally, it remains to be seen in what way the experience of life-long bilingualism takes effect at different levels of multitasking, in other words, whether bilingualism can offset the cognitive cost of multitasking at higher levels of performance compared to monolinguals, and if so, how much bilingual experience is necessary to have such differential effects. As Adler and Benbunan-Fich (2012) have shown, participants' improvement on task performance during multitasking at lower levels, attributed to increased arousal and, consequently, enhanced alertness induced by the multitasking environment, is lost at higher levels of multitasking due to growing between-task interference. One may adduce that bilinguals should be able to maintain an enhanced state of alertness at even higher levels of multitasking than monolinguals. Such differences will, however, be strongly linked to the quantity and quality of bilingual language input, particularly in children, in whom both language and EF are still developing. How often a bilingual individual regularly switches between languages and how proficient this individual is in each language will have a major impact on the development of EF and, by extension, on multitasking capacity.

\section{Acknowledgments}

This work was funded by grant R01HD052523 from the US National Institutes of Health to EB. We are grateful to Geoff Sorge for his contribution to this study.

\section{References}

Abutalebi J. Neural aspects of second language representation and language control. Acta Psychologica. 2007; 128:466-478. [PubMed: 18479667]

Abutalebi J, Green DW. Bilingual language production. The neurocognition of language representation and control. Journal of Neurolinguistics. 2007; 20:242-275.

Abutalebi J, Green DW. Control mechanisms in bilingual language production: Neural evidence from language switching studies. Language and Cognitive Processes. 2008; 23:557-582.

Abutalebi J, Annoni JM, Zimine I, Pegna AJ, Seghier ML, Lee-Jahnke H, Lazeyras F, Cappa SF, Khateb A. Language control and lexical competition in bilinguals: An event-related FMRI study. Cerebral Cortex. 2008; 18:1496-1505. [PubMed: 17947346]

Abutalebi J, Della Rosa PA, Castro Gonzaga AK, Keim R, Costa A, Perani D. The role of the left putamen in multilingual language production. Brain \& Language. 2013; 125:307-315. [PubMed: 22538086]

Abutalebi J, Della Rosa PA, Green DW, Hernandez M, Scifo P, Keim R, Cappa SF, Costa A. Bilingualism tunes the anterior cingulate cortex for conflict monitoring. Cerebral Cortex. 2012; 22:2076-2086. [PubMed: 22038906]

Adesope OO, Lavin T, Thompson T, Ungerleider C. A systematic review and meta-analysis of the cognitive correlates of bilingualism. Review of Educational Research. 2010; 80:207-245.

Adler RF, Benbunan-Fich R. Juggling on a high wire: Multitasking effects on performance. International Journal of Human-Computer Studies. 2012; 70:156-168.

Adi-Japha E, Berberich-Artzi J, Libnawi A. Cognitive flexibility in drawings of bilingual children. Child Development. 2010; 81:1356-1366. [PubMed: 20840226]

Allport, DA.; Styles, EA.; Hsieh, S. Shifting attentional set: Exploring the dynamic control of tasks. In: Umilta, C.; Moscovitch, M., editors. Attention and performance XV: Conscious and nonconscious information processing. Hillsdale, NJ: Erlbaum; 1994. p. 421-452.

Bhatia, TK.; Ritchie, WC. The Handbook of Bilingualism and Multilingualism. 2nd. Oxford: WileyBlackwell; 2013. 
Bialystok E. Coordination of executive functions in monolingual and bilingual children. Journal of Experimental Child Psychology. 2011; 110:461-468. [PubMed: 21683958]

Bialystok E, Barac R. Bilingual effects on cognitive and linguistic development: Role of language, cultural background, and Education. Child Development. 2012; 83:413-422. [PubMed: 22313034]

Bialystok E, Craik FIM, Green DW, Gollan TH. Bilingual minds. Psychological Science in the Public Interest. 2009; 10:89-129.

Bialystok E, Craik FIM, Klein R, Viswanathan M. Bilingualism, aging, and cognitive control: Evidence from the Simon task. Psychology and Aging. 2004; 19:290-303. [PubMed: 15222822]

Bialystok E, Craik FIM, Luk G. Lexical access in bilinguals: Effects of vocabulary size and executive control. Journal of Neurolinguistics. 2008; 21:522-538.

Blumenfeld H, Marian V. Bilingualism influences inhibitory control in auditory comprehension. Cognition. 2011; 118:245-257. [PubMed: 21159332]

Bobb SC, Wodniecka Z. Language switching in picture naming: What asymmetric switch costs (do not) tell us about inhibition in bilingual speech planning. Journal of Cognitive Psychology. 2013; 5:568-585.10.1080/20445911.2013.792822

Carlson SM, Meltzoff AN. Bilingual experience and executive functioning in young children. Developmental Science. 2008; 11:282-298. [PubMed: 18333982]

Costa, A. Lexical access in bilingual production. In: Kroll, JF.; de Groot, AMB., editors. Handbook of Bilingualism: Psycholinguistic Approaches. Oxford: Oxford University Press; 2005. p. 308-325.

Costa A, Santesteban M. Lexical access in bilingual speech production: Evidence from language switching in highly proficient bilinguals and L2 learners. Journal of Memory \& Language. 2004; 50:491-511.

Costa A, Hernández M, Sebastián-Gallés N. Bilingualism aids conflict resolution: Evidence from the ANT task. Cognition. 2008; 106:59-86. [PubMed: 17275801]

Costa A, Santesteban M, Ivanova I. How do highly proficient bilinguals control their lexicalization process? Inhibitory and language-specific selection mechanisms are both functional. Journal of Experimental Psychology: Learning, Memory \& Cognition. 2006; 32:1057-1074.

Duñabeitia JA, Hernández JA, Antón E, Macizo P, Estévez A, Fuentes LJ, Carreiras M. The inhibitory advantage in bilingual children revisited: Myth or reality? Experimental Psychology. 2014; 61:234-251.10.1027/1618-3169/a000243 [PubMed: 24217139]

Dunn, LM.; Dunn, LM. Peabody Picture Vocabulary Test. 3rd. Circle Pines, MN: American Guidance Service; 1997.

Emmorey K, Luk G, Pyers JE, Bialystok E. The source of enhanced cognitive control in bilinguals: Evidence from bimodal bilinguals. Psychological Science. 2008; 19:1201-1206. [PubMed: 19121123]

Eriksen BA, Eriksen CW. Effects of noise letters upon the identification of a target letter in a nonsearch task. Perception Psychophysics. 1974; 16:143-149.

Garbin G, Sanjuan A, Forn C, Bustamante JC, Rodriguez-Pujadas A, Belloch V, Hernández M, Costa A, Ávila C. Bridging language and attention: Brain basis of the impact of bilingualism on cognitive control. Neuroimage. 2010; 53:1272-1278. [PubMed: 20558314]

Garon N, Bryson SE, Smith IM. Executive function in preschoolers: A review using an integrative framework. Psychological Bulletin. 2008; 134:31-60. [PubMed: 18193994]

Gold BT, Kim C, Johnson NF, Kriscio RJ, Smith CD. Lifelong bilingualism maintains neural efficiency for cognitive control in aging. Journal of Neuroscience. 2013; 33:387-396. [PubMed: 23303919]

Green DW. Mental control of the bilingual lexicosemantic system. Bilingualism: Language and Cognition. 1998; 1:67-81.

Hernández M, Costa A, Fuentes LJ, Vivas AB, Sebastián-Gallés N. The impact of bilingualism on the executive control and orienting networks of attention. Bilingualism: Language and Cognition. 2010; 9:315-325.

Koch I, Gade M, Schuch S, Philipp AM. The role of inhibition in task switching: A review. Psychonomic Bulletin \& Review. 2010; 17:1-14. [PubMed: 20081154] 
Kovács ÁM, Mehler J. Cognitive gains in 7-month-old bilingual infants. Proceedings of the National Academy of Sciences of the United States of America. 2009; 106:6556-6560. [PubMed: 19365071]

Kroll JF, Bobb SC, Misra M, Guo T. Language selection in bilingual speech: Evidence for inhibitory processes. Acta Psychologica. 2008; 128:416-430. [PubMed: 18358449]

Kroll, JF.; Dussias, PE.; Bogulski, CA.; Valdes-Kroff, J. Juggling two languages in one mind: What bilinguals tell us about language processing and its consequences for cognition. In: Ross, B., editor. The Psychology of Learning and Motivation. Vol. 56. San Diego: Academic Press; 2012. p. 229-262.

Luk G, Bialystok E. Bilingualism is not a categorical variable: Interaction between language proficiency and usage. Journal of Cognitive Psychology. 2013; 25:605621.10.1080/20445911.2013.795574 [PubMed: 24073327]

Luk G, Green DW, Abutalebi J, Grady CL. Cognitive control for language switching in bilinguals: A quantitative meta-analysis of functional neuroimaging studies. Language and Cognitive Processes. 2012; 27:1479-1488. [PubMed: 24795491]

Marian V, Spivey M, Hirsch J. Shared and separate systems in bilingual language processing: Converging evidence from eyetracking and brain imaging. Brain and Language. 2003; 86:70-82. [PubMed: 12821416]

Martin-Rhee MM, Bialystok E. The development of two types of inhibitory control in monolingual and bilingual children. Bilingualism: Language \& Cognition. 2008; 11:81-93.

Marzecová A, Asanowicz D, Krivá L, Wodniecka Z. The effects of bilingualism on efficiency and lateralization of attentional networks. Bilingualism: Language and Cognition. 2013; 6:608-623.

Mechelli A, Crinion JT, Noppeney U, O'Doherty J, Ashburner J, Frackowiack RS, Price CJ. Structural plasticity in the bilingual brain. Nature. 2004; 431:757. [PubMed: 15483594]

Meuter RFI, Allport A. Bilingual language switching in naming: Asymmetrical costs of language selection. Journal of Memory and Language. 1999; 40:25-40.

Miyake A, Friedman NP. The Nature and Organization of Individual Differences in Executive Functions: Four General Conclusions. Current Directions in Psychological Science. 2012; 21 :814. [PubMed: 22773897]

Miyake A, Friedman NP, Emerson MJ, Witzki AH, Howerter A, Wager TD. The unity and diversity of executive functions and their contributions to complex "frontal lobe" tasks: A latent variable analysis. Cognitive Psychology. 2000; 41:49-100. [PubMed: 10945922]

Monsell S. Task switching. Trends in Cognitive Sciences. 2003; 7:134-140. [PubMed: 12639695]

Nicolay AC, Poncelet M. Cognitive advantage in children enrolled in a second-language immersion elementary school program for 3 years. Bilingualism: Language and Cognition. 2012; 16:597-607.

Pelham SD, Abrams L. Cognitive advantages and disadvantages in early and late bilinguals. Journal of Experimental Psychology: Learning, Memory and Cognition. 2014; 40:313-325.

Philipp AM, Gade M, Koch I. Inhibitory processes in language switching? Evidence from switching language-defined response sets. European Journal of Cognitive Psychology. 2007; 19:395-416.

Poarch GJ, Van Hell JG. Cross-language activation in children's speech production: Evidence from second language learners, bilinguals, and trilinguals. Journal of Experimental Child Psychology. 2012a; 111:419-438. [PubMed: 22138311]

Poarch GJ, Van Hell JG. Executive functions and inhibitory control in multilingual children: Evidence from second language learners, bilinguals, and trilinguals. Journal of Experimental Child Psychology. 2012b; 113:535-551. [PubMed: 22892367]

Poulin-Dubois D, Blaye A, Coutya J, Bialystok E. The effects of bilingualism on toddlers' executive functioning. The Journal of Experimental Child Psychology. 2011; 108:567-726.

Prior A, Gollan TH. Good language switchers are good task-switchers: Evidence from Spanish-English and Mandarin-English bilinguals. Journal of the International Neuropsychological Society. 2011; 17:682-691. [PubMed: 22882810]

Prior A, MacWhinney B. A bilingual advantage in task switching. Bilingualism: Language and Cognition. 2011; 13:253-262.

Raven, J.; Raven, JC.; Court, JH. Manual for Raven's Progressive Matrices and Vocabulary Scales. San Antonio, TX: Harcourt Assessment; 1998. updated 2003 
Rodriguez-Fornells A, Rotte M, Heinze HJ, Nösselt T, Münte TF. Brain potential and functional MRI evidence for how to handle two languages with one brain. Nature. 2002; 415:1026-1029. [PubMed: 11875570]

Salvucci DD, Taatgen NA. Threaded cognition: An integrated theory of concurrent multitasking. Psychological Review. 2008; 115:101-130. [PubMed: 18211187]

Salvucci, DD.; Taatgen, NA. The Multitasking Mind. New York: Oxford University Press; 2011.

Salvucci, DD.; Taatgen, NA.; Borst, JP. Human Factors in Computing Systems: CHI 2009 Conference Proceedings. New York: ACM Press; 2009. Toward a unified theory of the multitasking continuum: From concurrent performance to task switching, interruption, and resumption; $\mathrm{p}$. 1819-1828.

Schneider DW, Anderson JR. Asymmetric switch costs as sequential difficulty effects. Quarterly Journal of Experimental Psychology. 2010; 63:1873-1894.

Sebastián-Gallés N, Albareda-Castellot B, Weikum WM, Werker JF. A bilingual advantage in visual language discrimination in infancy. Psychological Science. 2012; 23:994-999. [PubMed: 22810164]

Stocco A, Yamasaki B, Natalenko R, Prat CS. Bilingual brain training: A neurobiological framework of how bilingual experience improves executive function. International Journal of Bilingualism. 2014; 18:67-92.10.1177/1367006912456617

Stuss DT. Functions of the frontal lobes: Relation to executive functions. Journal of the International Neuropsychological Society. 2011; 17:759-765. [PubMed: 21729406]

Stuss, DT.; Benson, DF. The frontal lobes. New York: Raven Press; 1986.

Thierry G, Wu YJ. Brain potentials reveal unconscious translation during foreign-language comprehension. Proceedings of the National Academy of Sciences of the United States of America. 2007; 104:12530-12535. [PubMed: 17630288]

Vandierendonck A, Liefooghe B, Verbruggen F. Task switching: Interplay of reconfiguration and interference control. Psychological Bulletin. 2010; 136:601-626. [PubMed: 20565170]

Van Heuven WJB, Schriefers H, Dijkstra T, Hagoort P. Language conflict in the bilingual brain. Cerebral Cortex. 2008; 8:2706-2716. [PubMed: 18424776]

Watson JM, Strayer DL. Supertaskers: Profiles in extraordinary multitasking ability. Psychonomic Bulletin \& Review. 2010; 17:479-485. [PubMed: 20702865]

Wiseheart M, Viswanathan M, Bialystok E. Flexibility in task switching by monolinguals and bilinguals. Bilingualism: Language and Cognition. in press.

Weikum WM, Vouloumanos A, Navarra J, Soto-Faraco S, Sebastián-Gallés N, Werker JF. Visual language discrimination in infancy. Science. 2007; 316:1159. [PubMed: 17525331]

$\mathrm{Wu}$ YJ, Thierry G. Unconscious translation during incidental foreign language processing. Neuroimage. 2012; 59:3468-3473. [PubMed: 22155033]

Yang S, Yang H, Lust B. Early childhood bilingsualism leads to advances in executive attention: Dissociating culture and language. Bilingualism, Language and Cognition. 2011; 14:412-422.

Yeung N, Monsell S. The effects of recent practice on task switching. Journal of Experimental Psychology: Human Perception and Performance. 2003; 29:919-936. [PubMed: 14585014] 


\section{Highlights}

- Constant use of two languages creates a situation of multitasking for bilingual children

- Multitasking recruits the executive control system

- New data are presented showing a bilingual advantage in an executive control task

- Full bilingualism was necessary for this advantage to emerge 


\section{Table 1}

Mean scores (and standard deviations) for background measures by language group.

\begin{tabular}{|c|c|c|c|c|}
\hline & Monolinguals & Partial Bilinguals & Bilinguals & Trilinguals \\
\hline$n$ & 60 & 44 & 60 & 39 \\
\hline Age & $9.5(1.0)$ & $9.7(0.8)$ & $9.4(0.8)$ & $9.6(1.0)$ \\
\hline Home language environment $a$ & $1.2(0.2)$ & $1.7(0.7)$ & $3.0(1.2)$ & $3.3(1.4)$ \\
\hline Mother's education $b$ & $3.8(1.2)$ & $3.8(1.3)$ & $3.7(1.4)$ & $3.2(1.4)$ \\
\hline Father's education $b$ & $3.7(1.2)$ & $3.8(1.2)$ & $3.7(1.4)$ & $3.5(1.2)$ \\
\hline PPVT standard score & $105.9(13.4)$ & $101.6(16.7)$ & $106.5(14.9)$ & $102.7(20.7)$ \\
\hline Raven's standard score & $102.0(14.2)$ & $101.9(15.8)$ & $105.7(14.9)$ & $100.4(15.6)$ \\
\hline
\end{tabular}

${ }^{a}$ Home language environment was quantified using a 7-point scale where 1 = "All English", 4 = "Half English, half other language(s)", and 7 = "Only in other language".

${ }^{b}$ Education was quantified using a 5-point scale where $1=$ no high school diploma, $2=$ high school graduate, $3=$ some college or college diploma, $4=$ bachelor's degree, and $5=$ graduate degree. 
Table 2

Mean RT and accuracy scores (and standard deviations) in flanker task by language group.

\begin{tabular}{lllll}
\hline \multicolumn{5}{c}{ Language Group } \\
\cline { 2 - 5 } Condition & Monolinguals & Partial Bilinguals & Bilinguals & Trilinguals \\
\hline RT & & & & \\
Baseline & $507(94)$ & $522(93)$ & $528(101)$ & $527(88)$ \\
Neutral & $646(94)$ & $654(77)$ & $645(95)$ & $632(86)$ \\
Mixed & & & & \\
(a) Congruent & $665(118)$ & $683(103)$ & $699(114)$ & $678(104)$ \\
(b) Incongruent & $769(129)$ & $784(110)$ & $748(105)$ & $740(100)$ \\
(c) Conflict (b-a) & 104 & 101 & 49 & 62 \\
\hline Accuracy & & & & \\
Baseline & $.93(.09)$ & $.95(.06)$ & $.94(.06)$ & $.95(.08)$ \\
Neutral & $.93(.09)$ & $.95(.04)$ & $.94(.07)$ & $.94(.07)$ \\
Mixed & & & & \\
(a) Congruent & $.95(.09)$ & $.96(.06)$ & $.96(.05)$ & $.96(.05)$ \\
(b) Incongruent & $.89(1.0)$ & $.92(.07)$ & $.91(.07)$ & $.92(.07)$ \\
(c) Conflict (b-a) & .06 & .04 & .05 & .04 \\
\hline
\end{tabular}

